
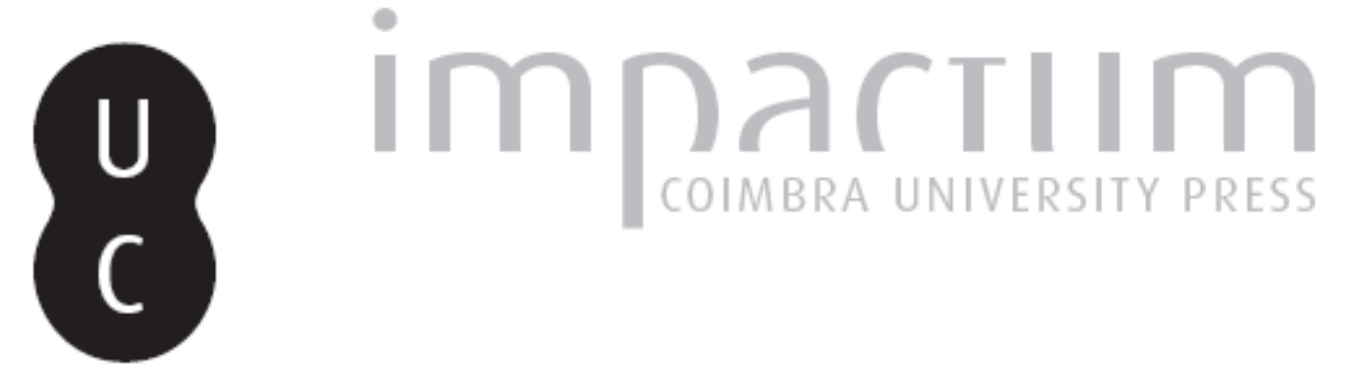

Alexandre Fradique Gomes de Oliveira Morujão (1922-2009)

Autor(es): $\quad$ Ribeiro, Henrique Jales

Publicado por: Faculdade de Letras da Universidade de Coimbra, Instituto de Estudos Filosóficos

URL persistente:

URI:http://hdl.handle.net/10316.2/33354

DOI:

DOI:http://dx.doi.org/10.14195/0872-0851_36_1

Accessed : $\quad$ 26-Apr-2023 01:24:53

A navegação consulta e descarregamento dos títulos inseridos nas Bibliotecas Digitais UC Digitalis, UC Pombalina e UC Impactum, pressupõem a aceitação plena e sem reservas dos Termos e Condições de Uso destas Bibliotecas Digitais, disponíveis em https://digitalis.uc.pt/pt-pt/termos.

Conforme exposto nos referidos Termos e Condições de Uso, o descarregamento de títulos de acesso restrito requer uma licença válida de autorização devendo o utilizador aceder ao(s) documento(s) a partir de um endereço de IP da instituição detentora da supramencionada licença.

Ao utilizador é apenas permitido o descarregamento para uso pessoal, pelo que o emprego do(s) título(s) descarregado(s) para outro fim, designadamente comercial, carece de autorização do respetivo autor ou editor da obra.

Na medida em que todas as obras da UC Digitalis se encontram protegidas pelo Código do Direito de Autor e Direitos Conexos e demais legislação aplicável, toda a cópia, parcial ou total, deste documento, nos casos em que é legalmente admitida, deverá conter ou fazer-se acompanhar por este aviso.

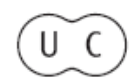




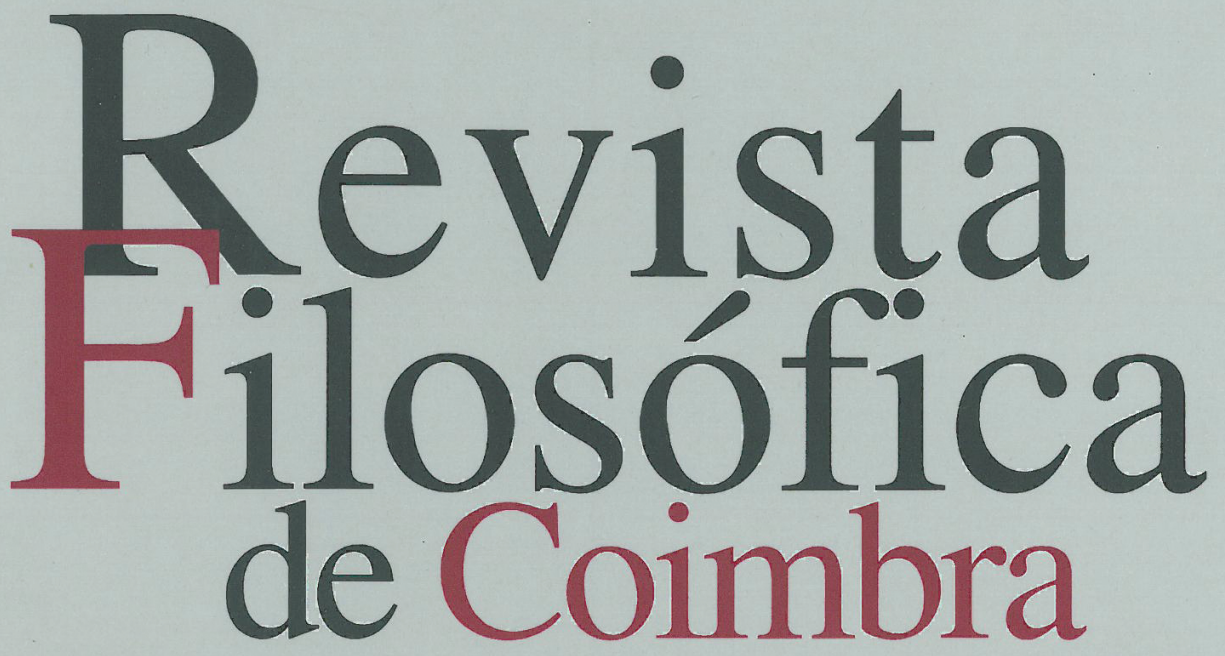

vol.19|n.036 | 2009

Henrique Jales Ribeiro Mario Santiago de Carvalho Edmundo Balsemão Pires Miquel Beltrán Ivo Oliveira 


\title{
ALEXANDRE FRADIQUE GOMES DE OLIVEIRA MORUJÃO
} (1922-2009)

\author{
HENRIQUE JALES RIBEIRO*
}

Alexandre Fradique Gomes de Oliveira Morujão, Professor Catedrático jubilado da Faculdade de Letras da Universidade de Coimbra, faleceu em 19 de Junho de 2009. Deixou connosco a seu respeito uma vasta, rica e grata memória. - A presente notícia foi escrita por Henrique Jales Ribeiro, seu aluno de licenciatura, de mestrado e de doutoramento. Não pretende ser uma descrição e muito menos uma análise da obra do saudoso Professor, cuja importância já foi sugerida pela mão de um dos mais fiéis depositários do seu legado filosófico (o Doutor Carlos Morujão, da Universidade Católica Portuguesa, Lisboa) ${ }^{1}$, mas um breve e seguramente modesto testumunho pessoal e intelectual de alguns dos aspectos da sua personalidade, como professor, como investigador e como homem.

\section{O Professor, o Investigador, o Homem}

Alexandre Morujão repartiu a sua actividade de Professor (aulas, seminários, conferências, orientação de teses) pela Universidade de Coimbra, que foi sem dúvida a sua casa principal e de eleição durante mais de quarenta anos, pela Universidade Católica Portuguesa e, episodicamente, pela Universidade dos Açores (ao abrigo de convénios

\footnotetext{
* Departamento de Filosofia, Comunicação e Informação (Faculdade de Letras da Universidade de Coimbra).

1 Veja-se Alexandre F. Morujão, Estudos Filosóficos, organização e prefácio de Carlos Morujão, Imprensa Nacional Casa da Moeda, Lisboa, vol. I (2002), vol II (2004).
} 
celebrados com a de Coimbra). O seu trabalho docente e o de investigação estiveram desde o início estreitamente relacionados, como aconteceu com muitos filósofos relevantes no passado e é suposto que aconteça com a generalidade dos professores universitários hoje em dia. Contudo, para ele o primeiro era não só uma condição essencial da sua própria criatividade filosófica e, como vou sugerir, da que perspectivava para os alunos, mas também uma missão ética cujos fundamentos, em última análise, não serão muito diferentes dos da Universidade ela mesma ao longo da sua história, quero dizer, de uma Universidade aí projectada e compreendida, tanto quanto é possível fazê-lo circunstancialmente, à luz das exigências (sempre problemáticas, sempre discutíveis) da nossa época. Por outras palavras, Alexandre Morujão via o património histórico e intelectual da Universidade de Coimbra, como fazendo parte, à sua maneira, do seu próprio património espiritual como Professor e como cidadão. Era essa soberba pretensão que fazia a sua humildade e modéstia, para aqueles que tiveram a honra de com ele lidar pessoalmente. De uma certa forma, à luz desta representação o Professor universitário, e em especial o de filosofia, encarna historicamente a ideia de Universidade desde as suas origens à actualidade, com tudo aquilo que ela terá de bom ou de mau. Cumpre-lhe, através do seu ensinamento, ser o principal agente do destino histórico multissecular da Universidade como a instituição e o local por excelência onde se concentra o saber das épocas passadas e de onde se difunde o da sua, em todas as respectivas valências e competências. É uma tal ideia que, em Coimbra, é quase misticamente sugerida pela magnificência da arquitectura da Universidade e sua envolvência, da Biblioteca Joanina à Sala dos Capelos, mesmo sem nos apercebermos disso quando por lá passamos. Cumpre-lhe ainda, muito particularmente, ser capaz de, se for o caso disso, intervir nesse destino, inflectindo-o e reorientando-o no melhor sentido, ou de acordo com o que pensa serem os grandes desafios do seu tempo. Fazendo-o, não só faz parte da história universal como tem um lugar privilegiado no curso ou desenvolvimento da mesma ${ }^{2}$. A Universidade, assim concebida, é a "casa" do Professor, de um modo por ventura não menos fundamental do que a sua própria casa ou residência familiar. Foi ao serviço dessa Universidade que, enquanto Professor, se colocou exemplarmente Alexandre Morujão.

\footnotetext{
2 Veja-se, neste sentido, "A filosofia na formação do universitário" e "A Universidade e a cultura", in idem, ibidem, vol. II, respectivamente, pp. 163-176, e 177-190.

3 Veja-se "A ontologia concreta de Gabriel Marcel" e "A intersubjectividade em Gabriel Marcel”, in idem, ibidem, vol. II, respectivamente, pp. 423-448, e 449-464.
} 
Esta concepção do que a Universidade é poderá ser causar-nos alguma estranheza hoje em dia, na medida em que tende-se por vezes a identificá-la apenas com o seu papel numa formação predominantemente técnica e/ou profissional das novas gerações para o mercado de trabalho, empobrecendo e reduzindo o do Professor nas suas múltiplas e diferentes vertentes, por sua vez, à condição económica e financeira da "prestação de serviços". Não será descabido nem exagerado dizer, deste ponto de vista, que muitos de nós (docentes e Professores) actualmente, no início do século XXI, de certo modo deixámos de acreditar na Universidade no sentido em que Alexandre Morujão e outros, nossos Mestres, acreditaram nela ao longo das suas vidas. A mística, segundo alguns, terá dado lugar à formalidade e/ou ao protocolo; e o ensino, perdendo em grande parte a nobreza que the foi inerente ao longo dos séculos, terá cedido o passo aqui e ali a uma investigação comandada simplesmente pelos objectivos de rentabilidade e sucesso imediato. Seja como for, depois do que fica dito, parece ser claro que a actividade docente e a investigação, de Alexandre Morujão, estão muito longe de poder ser assimiladas a meras funções ou ofícios profissionais. Depositava nelas a sabedoria de um filósofo apaixonado e o empenho existencial de um homem bom e generoso. Ele próprio, contra o funcionalismo crescente da Universidade e da nossa sociedade, contra, sobretudo, a desumanização do saber de forma geral, gostava de invocar nos seus cursos de licenciatura sobre Filosofia Contemporânea, e nos de mestrado em particular, as ilações que os seus alunos poderiam tirar, a propósito, quer da filosofia de Husserl e da de Heidegger quer, em particular, da de Gabriel Marcel ${ }^{3}$. Foi desse modo filosófico por excelência que ele encarou publicamente, desde os seus primeiros trabalhos, tais actividades. Foi também assim que sempre o admirei e continuo a admirar como Professor, desde que tive a honra de o conhecer, como aluno, já lá vão trinta anos.

As suas aulas de Lógica ou as de Filosofia Contemporânea, em Coimbra, por altura do ano de 1979-1980 (em que comecei por ser seu aluno), tinham aquela mesma exigência de rigor e clareza que caracterizam a filosofia de Husserl, que foi o grande motivo inspirador das suas investigações académicas. A essa filosofia, como se sabe, dedicou as suas dissertações de licenciatura e de doutoramento, e uma boa parte das suas publicações posteriores ${ }^{4}$. Mas também, sem dúvida, a sua licenciatura em Engenharia Electrotécnica pela Universidade do Porto no ano de 1947, antes de ter concluído a de Histórico-Filosóficas pela Universidade de

\footnotetext{
${ }^{4}$ Veja-se todo o vol. I dos Estudos Filosóficos e, desde logo, a "Introdução" de Carlos Morujão ao mesmo (pp. 7-16).
} 
Coimbra (1954), de certa forma impunha à sua docência um tal desiderato. Duas horas de prelecção sempre abertas a questões e dificuldades da parte dos alunos, e encarando cada um destes como um verdadeiro interlocutor. No curso de Lógica (cadeira anual, na época), primeira parte: um autor relevante para a história da disciplina; segunda parte: lógica proposicional. Pequenas cábulas escritas cuidadosamente à mão, que ele próprio confiava aos alunos mais displicentes por altura dos exames, guiavam o seu ensinamento. Exposições orais e escritas por parte dos alunos eram programadas e incentivadas ao longo do curso. Recordo-me que, uma vez, não existindo nenhum aluno a oferecer-se para o efeito, Alexandre Morujão saiu abruptamente da sala logo depois da aula ter começado, perante o olhar incrédulo de todos, despedindo-se com as palavras: "Então não estou aqui a fazer nada!" A exigência e a severidade, porém, eram nele apenas uma propedêutica para a aprendizagem filosófica e uma terapêutica para a prossecução da mesma. A regra era abertura e disponibilidade permanentes, de que são exemplos paradigmáticos as orais dos exames das cadeiras que leccionava, ou a recepção dos alunos mais preocupados e interessados, se fosse o caso disso, em sua casa. Nas orais, Alexandre Morujão fazia as perguntas de forma transparente e diligente, de acordo com o grau previsível de preparação dos alunos, mas, perante esta ou aquela dificuldade dos mesmos, ele próprio ia dando socraticamente as respostas, procurando sempre conduzir tão longe quanto possível o seu ensinamento filosófico. Era uma forma respeitadora por excelência da dignidade do saber filosófico em si mesmo e uma expressão delicadíssima de confiança nas capacidades dos examinandos. Em casa, no seu gabinete mesmo logo à entrada, rodeado de centenas de livros, como se em cada um deles estivesse guardada uma chave para abrir as portas do saber que a Universidade representava, a mesma atenção reverente, o mesmo cuidado vigilante em guiar o aluno pelos caminhos da investigação filosófica, aconselhando, por vezes em matéria da vida pessoal, criticando, emprestando livros. Aí estive presente inúmeras vezes; e lá continuo a ir frequentemente, com alguma nostalgia, nas minhas memórias. Mas Alexandre Morujão punha o mesmo espírito de serviço na sua actividade como Presidente da Sociedade Filantrópico-Académica de Coimbra, que exerceu durante vários anos, face a face continuamente com as dificuldades e problemas de várias índoles dos/das estudantes da sua Universidade.

Eu tive a honra pessoalmente de ter vivido as diferentes situações a que acabo de aludir desde o ano de 1979 até ao de 1992, quando Alexandre Morujão se jubilou e, por força dessa condição, deixou de exercer o seu magistério. Durante alguns anos ainda orientou com uma dedicação impressionante a minha dissertação de doutoramento. Mas nada 
do que disse mais acima era novo para ele, na altura, como didáctica da filosofia. Num pequeno escrito do início dos anos cinquenta, "Um método de trabalho universitário: o regime de seminário", reflectindo sobre as perplexidades provocadas pela criação desse regime na Faculdade de Letras da Universidade de Coimbra, e combatendo os preconceitos académicos vigentes em relação às funções tradicionais do Professor (confiadas basicamente às "lições" ou às "prelecções magistrais"), Alexandre Morujão concluía da seguinte encantadora forma:

"Há-de, pois, o professor universitário de uma Faculdade de Letras receber em sua casa, em dia e hora determinados, os alunos que preparam trabalhos sob a sua orientação. Se nas aulas de seminário se colocou no plano dos discípulos, incitando-os, corrigindo-os, quebrando-lhes as amarras com que o orgulho, a timidez ou a preguiça os manietavam, revelando-lhe novos horizontes, despertando-lhes a curiosidade científica, agora, no ambiente discreto do seu gabinete pessoal, rodeado de seus papéis, de seus ficheiros, dos seus trabalhos em curso, revelar-lhes-á o que é a criação científica, o que são as técnicas de trabalho intelectual, não por discursos embora acompanhados do calor da persuasão, mas pelo exemplo, à maneira do artista com seus discípulos na laboriosidade do atelier." 5

Desse espírito de serviço ao seus alunos, que este texto bem exemplifica, ficam para a história não apenas as suas investigações na área da fenomenologia de Husserl ou na da filosofia em Portugal, mas também, de modo quiçá mais relevante, na dos estudos kantianos, com a tradução para português da Kritik der reinen Vernunft, de Immanuel Kant. Foi um trabalho de autêntica ourivesaria filosófica em que se empenhou pessoalmente durante mais de dez anos com a colaboração de Manuela Pinto dos Santos. E é um monumento de labor e dedicação a um dos maiores filósofos de todos os tempos, que passou a constituir um instrumento indispensável dos cursos de filosofia de todas as Universidades portuguesas.

\section{Sociedades e Centros Científicos a que Pertenceu Alexandre Morujão}

- Sócio-fundador e director da Secção de Filosofia da Sociedade Científica da Universidade Católica Portuguesa.

${ }^{5}$ Idem, ibidem, vol. II, p. 141. 
- Presidente da direcção do Centro de Estudos Fenomenológicos de Coimbra.

- Membro da Sociedade Internacional Francisco Suarez.

- Sócio efectivo do Instituto de Coimbra.

- Membro da Gottfried-Wilhelm-Leibniz-Gesellschaft de Hannover.

- Membro da direcção de 'Logos' - Enciclopédia Luso-Brasileira de Filosofia.

- Membro da Sociedade de Estudos Kantianos de Lisboa.

- Sócio efectivo de CELBRA - Centro de Estudos do Pensamento Luso-Brasileiro do Rio de Janeiro.

- Membro da International Phenomenological Society.

- Sócio-correspondente da Academia de Ciências de Lisboa (Maio 1988).

- Membro da Görres - Gesellschaft zur Pflege der Wissenschaft.

- Membro estrangeiro da Academia Brasileira de Filosofia (25 Nov. 1988).

- Sócio-fundador do Instituto de Filosofia Luso-Brasileira.

\section{Principais Trabalhos Publicados}

- "Introdução a Maurice Blondel. A filosofia da acção", in Estudos, XXVII, 1949.

- "Um método de trabalho universitário: o regime de seminário", in O Pensamento Católico e a Universidade (Actas do $1^{\circ}$ Congresso Nacional da Juventude Universitária), Lisboa, 1953.

- A doutrina da intencionalidade na fenomenologia de Husserl, Coimbra, 1955.

- "O'fenómeno puro', ponto de partida da fenomenologia de Husserl”, in Filosofia, IV, 1957.

- Mundo e intencionalidade. Ensaio sobre o conceito de mundo na fenomenologia de Husserl, Coimbra 1961.

- "Sobre a interpretação kantiana do belo e da arte", in Revista Portuguesa de Filosofia, XXIII, 1967.

- Subjectividade e história, Coimbra, 1969.

- Perspectivas do ensino livre, Coimbra, 1972.

- "Sobre a noção de finalidade na Crítica Kantiana da Faculdade de Julgar", in O Instituto, XXXVII, 1975.

- "Significado e estrutura da redução fenomenológica", in Biblos, LVI, 1980.

- "Fenómeno, númeno, coisa-em-si. Notas sobre os três conceitos kantianos", in Revista Portuguesa de Filosofia, XXXVII, 1981. 
- "A filosofia como saber rigoroso de fundamentação", in Revista Portuguesa de Filosofia, XXXVIII, 1982.

- "O sentido da filosofia em Leonardo de Coimbra", in Revista Portuguesa de Filosofia, XXXIX, 1983.

- "Pintura e filosofia", in Revista da Universidade de Coimbra, XXX, 1984.

- "Prefácio da tradução portuguesa da Crítica da Razão Pura", in Immanuel Kant, Crítica da Razão Pura, tradução do original em língua alemã por Alexandre F. Morujão e Manuela Pinto dos Santos, Lisboa, 1985.

- "O problema da intersubjectividade na fenomenologia de Husserl", in Actas do $2^{\circ}$ Colóquio Português de Fenomenologia, Revista Portuguesa de Filosofia, XL, 1985.

- "Nota sobre a refutação kantiana do idealismo", in Biblos, LXII, 1986.

- "Perspectivas e horizontes da antropologia filosófica", in Laikos, IX, 1987.

- "O itinerário filosófico de Sampaio Bruno", in Revista Portuguesa de Filosofia, XLII, 1987.

- "Ciência e filosofia no pensamento de Leonardo Coimbra", in $O$ pensamento filosófico de Leonardo Coimbra (Actas do Colóquio "Leonardo Coimbra", no cinquentenário da sua morte), Lisboa, 1989.

- "A intersubjectividade no pensamento de Gabriel Marcel", in Revista Portuguesa de Fiosofia, XLV, 1989.

- "Historicidade e filosofia", in Arquipélago, Ponta Delgada, 1985.

- "O sentido da finalidade na filosofia de Kant", in Pensar a Cultura, Lisboa, 1993.

- "Meio século de filosofia na Faculdade de Letras de Coimbra", in Revista Portuguesa de Filosofia, LI, 1995.

- "A dialéctica da acção em L'action (1983) de Maurice Blondel”, in Revista Portuguesa de Filosofia, LII, 1996.

\section{Traduções e Colaborações em Enciclopédias}

- Friedrich Stegmüller, Filosofia e Teologia em Coimbra e Évora no séc. XVI, tradução directa do alemão de "Studien zur Literargeschichte der Philosophie und Theologie an der Universitäten Coimbra und Évora im XVI. Jahrhundert", Universidade de Coimbra, VIII+472 páginas.

- Fritz Heinemann, A filosofia no século XX, tradução do original em língua alemã "Die Philosophie im XX Jahrhundert", Lisboa, 
Fundação Calouste Gulbenkian, 1983 ( $3^{\text {a }}$ ed.).

- Immanuel Kant,_Crítica da Razão Pura, tradução directa do alemão por Alexandre Fradique Morujão e Manuela Pinto dos Santos, Lisboa, Fundação Calouste Gulbenkian, 1996 (3 ${ }^{a}$ ed.).

- Colaboração em 'Verbo'-Enciclopédia Luso-Brasileira de Cultura, Editoral Verbo, Lisboa/São Paulo.

- Colaboração em 'Polis'-Enciclopédia Verbo da Sociedade e do Estado, Editorial Verbo, Lisboa/São Paulo.

- Colaboração em 'Logos'-Enciclopédia Luso-Brasileira de Filosofia, Editoral Verbo, Lisboa/São Paulo.

\section{Colectâneas}

- Alexandre F. Morujão, Estudos Filosóficos, organização e prefácio de Carlos Morujão, Imprensa Nacional Casa da Moeda, Lisboa, vol. I (2002), vol II (2004). 